\title{
Target and Neurotransmitter Specificity of Fetal Central Nervous System Transplants: Importance for Functional Reinnervation
}

\author{
J. L. Hudson, ${ }^{1}$ P. Bickford, ${ }^{1}$ M. Johansson, ${ }^{2}$ B. J. Hoffer, ${ }^{1}$ and I. Strömberg ${ }^{2}$ \\ 'Departments of Pharmacology and Psychiatry, University of Colorado Health Sciences Center, Denver, Colorado 80262 \\ and VAMC, Denver, CO 80262, and 'Department of Histology and Neurobiology, Karolinska Institutet, Stockholm, Sweden
}

The ability of grafted fetal ventral mesencephalic dopaminergic (DAergic) neuroblasts to reinnervate the unilaterally DA denervated rat striatum and improve motoric asymmetry has been well documented in several laboratories. The importance of host target specificity, and catecholamine (CA) neurotransmitter species, in the ability of grafts to ameliorate rotational responses to apomorphine and to affect electrophysiological characteristics of striatal neurons has not been systematically studied. We unilaterally lesioned SpragueDawley rats with 6-hydroxydopamine (6-OHDA) and verified the lesions using apomorphine $(0.05 \mathrm{mg} / \mathrm{kg}$, s.c.)-induced rotational behavior. Some of the animals subsequently received, intrastriatally, either DA neuroblasts from ventral mesencephalon that normally innervate the striatum, or from arcuate nucleus that do not. Additionally, two other groups were included that received either a CAergic graft from the noradrenergic nucleus locus coeruleus or a graft of cerebral cortex, which normally projects to the striatum but does not contain CAergic neurons. Only the fetal ventral mesencephalic grafts were able to reduce apomorphine-induced rotations and normalize striatal cell firing rates; striatal cell firing rates with ventral mesencephalic grafts were $1.43 \mathrm{~Hz}$ \pm 0.22 , with arcuate nucleus grafts were $6.03 \pm 0.73$, with locus coeruleus grafts were $4.71 \pm 0.74$, and with cerebral cortex grafts were $4.36 \pm 0.45$. Moreover, only the ventral mesencephalic grafts produced a dense tyrosine hydroxylase (TH)-immunoreactive nerve terminal network in the striatum; in contrast, the arcuate nucleus grafts did not reinnervate the striatum. In locus coeruleus grafted striata, few very long TH-positive axons were seen. We thus conclude that target specificity and neurotransmitter type are critically important in the ability of a graft to functionally reinnervate the 6-OHDA denervated striatum.

[Key words: fetal transplants, locus coeruleus, arcuate nucleus, substantia nigra, cerebral cortex, electrophysiology, immunohistochemistry, phencyclidine, specificity, behavior, rotation, 6-hydroxydopamine, striatum]

\footnotetext{
Received Jan. 4, 1993; revised May 6, 1993; accepted June 30, 1993.

This work was supported by U.S. Public Health Service Grants NS09199 and MH10015, the VA Research Service, the Swedish Medical Research Council Grants 08868 and 09917, and the Foundations of Lars Hierfas and Palle Ferbs Minne.

Correspondence should be addressed to Barry J. Hoffer, M.D., Department of Pharmacology, Campus Box C236, University of Colorado Health Sciences Center, 4200 East Ninth Avenue, Denver, CO 80262.

Copyright (C) 1994 Society for Neuroscience $0270-6474 / 94 / 140283-08 \$ 05.00 / 0$
}

During normal development, CNS areas possess very specific mechanisms to ensure that neurons project to appropriate targets. This is evident from the observations that neurons differentially innervate one portion of brain while concurrently avoiding adjacent parenchyma. For example, the dopaminergic (DAergic) neurons of the substantia nigra densely innervate the striatum while avoiding nearby basal ganglia regions (Strömberg et al., 1992). Similarly, corticospinal axons project a great distance, from cortex down to spinal motor neurons, through a great many structures without forming connections with them (Schreyer and Jones, 1982). Thus, the CNS provides an appropriate environment within which specific connections can be made. Several mechanisms have been hypothesized to account for specificity of fiber growth as well as connectivity, such as neuronal activity (Archer et al., 1982; Dubin et al., 1986; Shatz and Stryker, 1988; Sretavan et al., 1988), cell surface molecules (Weiss, 1947; Edelman, 1984a,b), growth or chemotactic factors (Ramon y Cajal, 1910, 1959; Levi-Montalcini, 1964), electrical fields (Jaffe and Nuccitelli, 1977; Robinson, 1985; Faber and Korn, 1989), and adjacent fibers (Lynch et al., 1972, 1976; Rutishauser et al., 1978), among others. Through these postulated mechanisms, the brain regulates the development of correctly functioning circuits, which are essential for normal brain organization and function.

Regulation of connectivity is largely not understood. Fetal CNS grafts provide a unique opportunity to examine some aspects of the regulation of the specificity for connections made during development. Brain grafting allows placement of differing immature CNS tissues in proximity to a denervated adult target, and determination of whether the graft is able to reinnervate the target. It is possible to vary the grafts with respect to target as well as neurotransmitter appropriateness. Thus, it is possible to compare the normal with abnormal inputs and to delineate the importance of neurotransmitter and target specificity in functional reinnervation. When grafted to the anterior chamber of the eye, various catecholamine (CA)-containing nuclei, such as the substantia nigra and locus coeruleus, make functional connections with appropriate but not inappropriate targets (Olson et al., 1979). However, it might be argued that the environment of the anterior chamber is significantly different from that of the CNS. Consequently, in this article, we have attempted to use fetal CAergic grafts to brain parenchyma in order to investigate the importance of neurotransmitter type and normal target appropriateness. In addition, intracerebral grafting allows use of physiological and behavioral indices of graft specificity, as well as the more commonly employed morphological measures. 
We have selected a well-defined target for these in situ grafts, the DA denervated striatum. Unilateral lesions of the DAergic input to the striatum in the rat, using medial forebrain bundle injections of 6-hydroxydopamine (6-OHDA), have been used as a model of neural degeneration and reinnervation for many years (Ungerstedt, 1968, 1971a,b; Stenevi et al., 1976). In this model, lesioned rats manifest DAergic receptor denervation supersensitivity of the striatum ipsilateral to the lesion. The level of DA depletion can be quantitated using a behavioral test. Low doses of DAergic agonists, such as apomorphine, will asymmetrically stimulate the striata and induce turning, the number of which roughly correlates with the level of DA denervation (Carman et al., 1991; Hudson et al., 1991). Grafts of fetal ventral mesencephalic neuroblasts are known to reduce DA agonistinduced turning, which is usually interpreted as a functional reinnervation of the DA denervated striata (Björklund and Stenevi, 1979; Perlow et al., 1979).

In conjunction with behavioral amelioration, fetal mesencephalic grafts also have the ability to normalize specific electrophysiologic properties of striatal neurons. One such parameter is the spontaneous discharge rate; DA denervated striatal cells manifest a severalfold increased basal firing rate as compared with normally innervated cells (Arbuthnott, 1974; Siggins et al., 1974; Nisenbaum et al., 1986; Orr et al., 1987). This may be due to a lack of inhibitory DAergic input to the striatal neurons that results in disinhibition. When functional reinnervation occurs from DA-containing grafts, the spontaneous discharge rate of striatal neurons is restored to normal (Strömberg et al., 1985; Fisher et al., 1991). A second electrophysiological parameter is the response to indirect DAergic agonists, such as phencyclidine (PCP). Low doses of PCP, administered locally, act at DAergic terminals to inhibit the reuptake of endogenously released DA (Gerhardt et al., 1987). In the DA denervated striata, no change in the striatal cell firing rates is apparent in response to local PCP application (Johnson et al., 1984). After grafting with fetal ventral mesencephalon, slowing of firing rate in response to PCP reappears (Strömberg et al., 1985), which provides further evidence of functional DAergic reinnervation.

Histologic studies can also document the extent and specificity of neurite outgrowth. Fetal ventral mesencephalic grafts into the DA denervated striatum exhibit extensive neurite outgrowth and tyrosine hydroxylase (TH) positivity while remaining dopamine $\beta$-hydroxylase (DBH) negative. Moreover, it has been shown histologically that ventral mesencephalic tissue reinnervates only areas that normally are innervated by DAergic neurons (Strömberg et al., 1992).

Specifically, the goals of the present study were to test if fetal DAergic neuroblasts from the arcuate nucleus, which do not normally innervate the striatum, or fetal noradrenergic (NAergic) neuroblasts from the locus coeruleus, which are a different CA neuronal type and which also do not normally innervate the striatum, would produce a similar functional reinnervation of the striatum as do grafts of fetal ventral mesencephalic DAergic neuroblasts, as detailed above. Additionally, as a further test of specificity, grafts of fetal cerebral cortex, containing non-DA neurons that normally project to the striatum, were also evaluated.

\section{Materials and Methods}

Lesioning and grafting procedures. Female Sprague-Dawley rats were DA denervated in striatum by unilateral injections of 6-OHDA $(8 \mu \mathrm{g} /$ $4 \mu \mathrm{l} / 4 \mathrm{~min}$ in normal saline containing $0.2 \mathrm{mg} / \mathrm{ml}$ ascorbic acid) into the medial forebrain bundle $(-4.4 \mathrm{~mm} \mathrm{AP}, 1.2 \mathrm{~mm} \mathrm{ML}$ relative to bregma, and $7.8 \mathrm{~mm}$ below the dural surface).

The rotational behavior was tested with low doses $(0.05 \mathrm{mg} / \mathrm{kg}$, s.c.) of apomorphine, using a multichannel rotometer system (Hudson et al., 1991), to evaluate the degree of DA depletion. Rats rotating greater than 500 turns after apomorphine injection, and showing a double peak, were selected for grafting. The animals were implanted, under halothane anesthesia, with fetal tissue (two pieces approximately $1 \mathrm{~mm}^{3}$ each) directly into the striatal parenchyma ( $+0.5 \mathrm{~mm}$ AP, $2.8 \mathrm{~mm} \mathrm{ML}$ relative to bregma, and $5.0 \mathrm{~mm}$ below the dural surface) using a 20 gauge canula. The crown-rump length (CRL) of the fetuses supplying ventral mesencephalic and arcuate nucleus-derived DAergic neuroblasts was 13$14 \mathrm{~mm}$. Those supplying noradrenergic neuroblasts from locus coeruleus were $18 \mathrm{~mm}$. Finally, the CRL of donor fetuses used for cerebral cortical grafts was $20-22 \mathrm{~mm}$. These fetal ages have been previously determined to be optimal for the respective regions transplanted.

Tests were administered initially at 2 weeks postgrafting, and again at 1,2 , and 3 months postgrafting. The cortical grafts were done at a different time and on a different population of lesioned rats than the other three groups.

Electrophysiological recordings. Transplanted animals were anesthetized with urethane $(1.25 \mathrm{~g} / \mathrm{kg}$, i.p.), tracheotomized, and placed into a stereotaxic frame. Body temperature was maintained at $36-38^{\circ} \mathrm{C}$ with a heating pad. The skin, skull, and dura ovcrlying lesioned and transplanted as well as control striata were removed and an opening made into the cisterna magna for drainage of cerebrospinal fluid to reduce brain pulsations. Cotton pellets soaked in normal saline were used to cover the brain surface and prevent drying.

Recordings were performed using single- or multibarrel glass micropipettes. The single-barrel pipettes, used to record basal firing rates, were filled with a $3 \mathrm{M} \mathrm{NaCl}$ solution. In double-barrel pipettes, the recording barrel was filled with $3 \mathrm{M} \mathrm{NaCl}$, containing $100 \mathrm{~mm}$ glutamate. This was used to augment the basal firing rates of striatal cells that fire slowly, in order to facilitate the quantitation of responses to local PCP administration. The other barrel was filled with the indirect dopamine receptor agonist $\mathrm{PCP}, 1 \mathrm{~mm}$ in normal saline at $\mathrm{pH} 7.2$. The resistance of all recording pipettes was between 1.8 and $2.4 \mathrm{M} \Omega$.

Ncuronal single action potcntials were amplified, filtered $(-3 \mathrm{~dB}$ at 0.3 and $10 \mathrm{kHz}$ ), and displayed on a storage oscilloscope. Action potentials were separated from background activity using a window discriminator; the output from the window discriminator was displayed on a strip-chart recorder and interspike-interval histograms were produced on line using an Apple IIe computer. PCP was locally applied by micropressure ejection and doses are reported as psi*sec (Gerhardt and Palmer, 1987). The effect of PCP was evaluated as a change in neuronal activity and local anesthetic artifacts were defined as transient decreases in spike height. "Responsive" cells were defined as cells that exhibited a dose-dependent decrease in firing rate, in excess of $50 \%$, prior to any change in spike morphology. "Nonresponsive" cells manifested a spike height change, with increasing PCP doses, in the absence of firing rate changes. Such changes in spike height with high doses were required to ensure that PCP was indeed ejected. Basal firing rates werc mcasurcd before any drug was applied to an individual cell.

Immunohistochemistry. Following electrophysiologic testing, animals were perfused with $100 \mathrm{ml}$ of $\mathrm{Ca}^{2+}$-free Tyrode solution followed by $4 \%$ paraformaldehyde solutions in $0.16 \mathrm{M}$ phosphate buffer containing $0.4 \%$ picric acid. Brains were postfixed, in the same fixative, for $1-2 \mathrm{hr}$ before rinsing in $10 \%$ sucrose buffer. Cryostat sections $(14 \mu \mathrm{m})$ were incubated in antibodies raised against TH (Pel Freeze) diluted 1:100 or DBH diluted 1:500 in phosphate-buffered saline (PBS) containing 0.3\% Triton for $40 \mathrm{hr}$ at $4^{\circ} \mathrm{C}$. After three rinses in PBS, sections were incubated in fluorescein isothiocyanate (FITC; Dako) or Cy III (Jackson Laboratories) conjugated secondary antibodies for $1 \mathrm{hr}$ at room temperature. After three additional rinsings, the sections were coverslipped in $90 \%$ glycerol in PBS containing $0.1 \% p$-phenylenediamine, to prevent fading (Johnson and Nogueira Araujo, 1981)

\section{Results}

Behavioral responses to subcutaneous apomorphine, in all grafted animals, are shown in Figure 1. The cerebral cortex grafts had a differing baseline rotational number and are therefore shown on the same graph with the right y-axis, indicating the rotational values for this group only. Comparison of this data to each group's pregrafting rotation level revealed that only the 


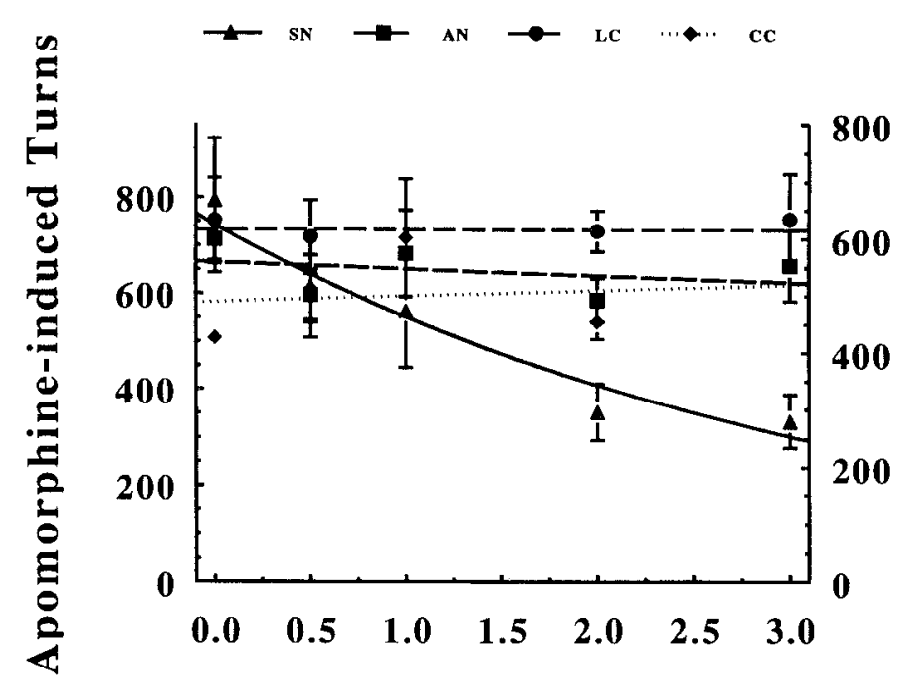

\section{Months After Transplants}

Figure 1. Transplant effects on turning behavior: rotational response to low-dose apomorphine injections $(0.05 \mathrm{mg} / \mathrm{kg}$, s.c.) in rats with unilateral 6-OHDA lesions of the nigrostriatal tract and subsequently grafted with fetal neuroblasts. Rats that received grafts of fetal ventral mesencephalon $(S N)$ showed a decrease of $50 \%$ in the number of apomorphine-induced rotations 2-3 months postgrafting, demonstrating a functional reinnervation of the striatum. Grafts of arcuate nucleus $(A N)$ DAergic neuroblasts, which do not normally innervate the striatum, did not produce a decrease in the number of apomorphine-induced rotations. A similar lack of functional reinnervation was observed with N $\Lambda$ grafts of locus cocrulcus $(L C)$ ncurons and non-CAcrgic grafts of cerebral cortical $(C C)$ neuroblasts. Cerebral cortical grafts were done at a different time and their rotational levels are reported on the right $y$-axis; the left axis shows rotation levels for the other three groups.

ventral mesencephalic grafted group showed a significant reduction in turning. The arcuate nucleus, locus coeruleus, and cerebral cortex groups manifested no change in rotational behavior for up to 3 months posttransplantation.

In order to define further the changes at the cellular level, basal firing rates of striatal cells were recorded for all transplanted striata and contralateral (control) striata. Figure 2 depicts the mean values and standard errors for each group. The control contralateral striatal values for ventral mesencephalic, arcuate nucleus, and locus coeruleus grafts were somewhat different than those for the cerebral cortical grafts and therefore both control values are indicated. The ventral mesencephalic grafts were able to normalize firing rates $(1.43 \pm 0.22 \mathrm{~Hz}, n=$ 26) to below control values $(2.23 \pm 0.40 \mathrm{~Hz}, n=17, t=1.89$, $p>0.05$ ), whereas the DAergic and NAergic grafts from arcuate nucleus $(6.03 \pm 0.73 \mathrm{~Hz}, n=40, t=3.31, p<0.01)$ and locus coeruleus $(4.71 \pm 0.74 \mathrm{~Hz}, n=34, t=2.30, p<0.05)$, respectively, were not. The grafts of cerebral cortex were also unable to reduce basal discharge rates $(4.36 \pm 0.45 \mathrm{~Hz}, n=16)$ to control rates $(1.04 \pm 0.19 \mathrm{~Hz}, n=10, t=5.60, p<0.01)$.

To define further the influence of graft CAcrgic input, PCP administration was also carried out. Striatal neuronal responses to local applications of PCP are shown in Figures 3 and 4. Figure 3 shows five ratemeter records of five different striatal neurons in grafted rats. Figure $3 a$ is from a ventral mesencephalic grafted animal. Firing rates decrease in a dose-dependent fashion in response to drug application. Figure $3 b$, from an arcuate nucleus grafted rat, shows nonresponsiveness to PCP application. Figure $3 c$ shows two ratemeter records of two different neurons in

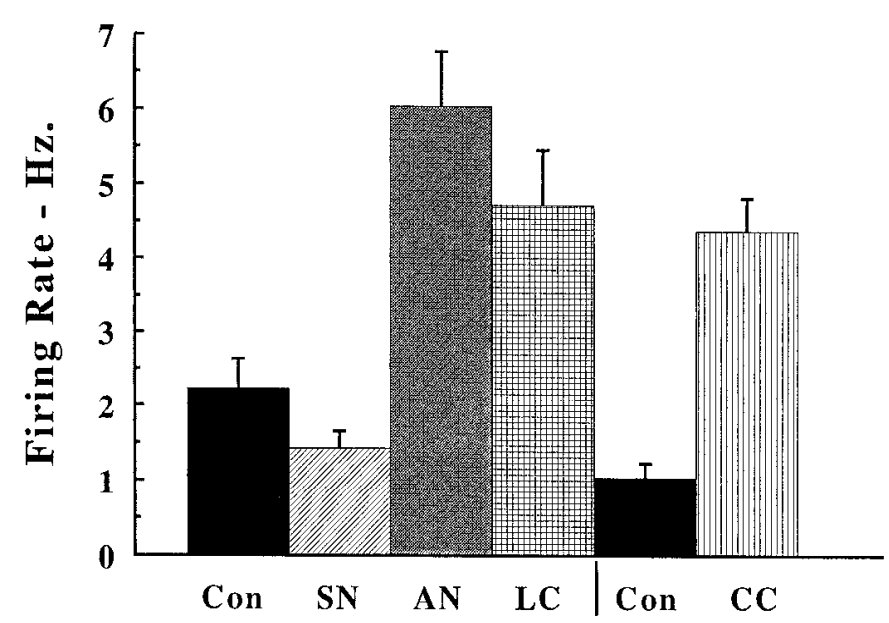

Figure 2. Graft effects on spontaneous striatal cell firing rates showing means and SEMs for spontaneous firing rates of striatal neurons postgrafting. The spontaneous firing rate of striatal neurons is increased after 6-OHDA lesions. Grafting of fetal mesencephalic neuroblasts $(S N)$ to the lesioned striatum results in a normalization of firing rates to control values. Grafts of arcuate nucleus $(A N)$, locus coeruleus $(L C)$, or cerebral cortex $(C C)$ do not normalize the firing rates of striatal neurons. The $\mathrm{SN}, \mathrm{AN}$, and LC graft recording series were performed on rats at the same time and the $\mathrm{CC}$ graft recording series was performed on rats at a different time. The contralateral nonmanipulated striatal control values $(C o n)$ for spontaneous discharge were different; thus, the data are separated for control and experimental parameters for the two series.

striata containing locus coeruleus transplants. The first trace shows a cell responsive to PCP application and the second shows a neuron that is unresponsivc; both neurons were located close to the graft. Similarly, Figure $3 d$ displays the record for a striatal cell in a striatum that has received a cerebral cortex graft; no response to PCP was manifested. The percentages of responsive cells either proximal, $0.5 \mathrm{~mm}$ from the graft tract, or distal, 1.0 $1.5 \mathrm{~mm}$ from the graft tract, are indicated in Figure 4. Cells were classified as nonresponding if the dose of PCP was increased to the point that an action potential amplitude decrease, indicating a local anesthetic action, was noted without a firing rate change. Responding neurons were defined as cells that decreased their discharge rate, in a reproducible and dose-dependent fashion, in response to local PCP application without a change in action potential amplitude.

Responding cells were found proximally and distally only in the ventral mesencephalic grafted striata and only adjacent to the transplants, in the locus coeruleus grafted striata. Both proximal and distal recording sites in the ventral mesencephalon grafted rats showed a high percentage of responding cells $(80 \%$ and $100 \%$, respectively). Proximally, in the locus coeruleus grafted striatum, there were $86 \%$ responding cells; distally no cells responded. Arcuate nucleus grafted striata showed $25 \%$ of the neurons responding proximally and none distally. Interestingly, no cells responded proximally in the cortex grafted animals, whilc distally $50 \%$ responded. Data from the cerebral cortex grafted striata may be ambiguous, however, because all the distal cells were recorded from the same electrode pass and may represent a residual spared endogenous DAergic fiber input.

In all rats, surviving transplants were found. The volumes of the transplants was estimated to be approximately the same for all four types of grafted tissue, and all graft types were well integrated into the host brain parenchyma. TH-positive neurons were found within the monoamine transplants (Fig. $5 a-c$ ), but 

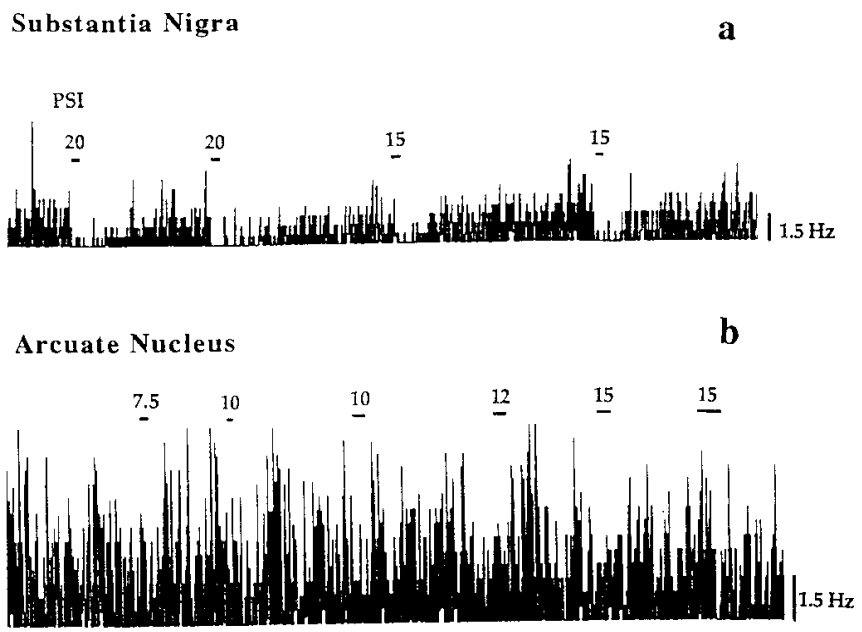

Locus Coeruleus
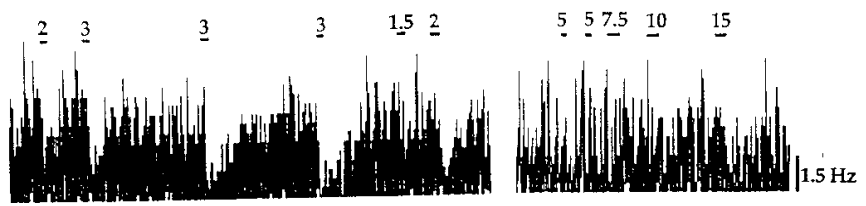

Cerebral Cortex

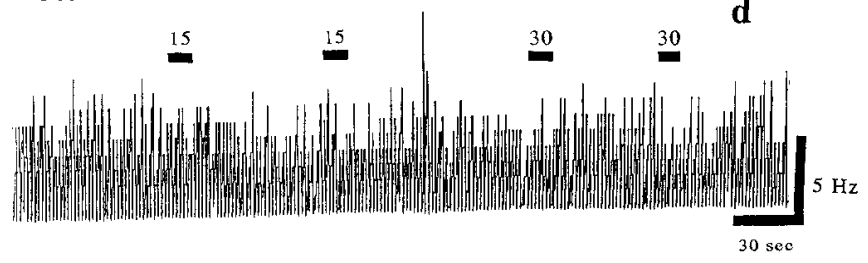

Figure 3. Ratemeter records of cells in transplanted striata, demonstrating the discharge of striatal neurons after local applications of PCP ( $1 \mathrm{~mm}$ barrel concentration, $\mathrm{pH}$ 7.2). When PCP was locally applied onto neurons in animals that had received grafts of fetal mesencephalic neurons $(a)$, it induced a dose-dependent inhibition of firing rate. Similar responses were obtained from some cells proximal to locus coeruleus grafts, an example of which is shown in the left side of $c$. The right side of $c$ shows the ratemeter record of an unresponsive cell in the same striatum. $b$ shows an example of unresponsive neurons from an arcuate nucleus grafted animal. $d$ is from a rat that had received a graft of fetal cerebral cortex, and shows an example of an unresponsive neuron. Bars above the graphs indicate the time of PCP application, and overlying numbers indicate ejection doses (psi). Horizontal calibration bars are the time in seconds; vertical calibration bars are the firing rates in spikes per second $(\mathrm{Hz})$.

DBH-immunoreactive cells could be detected only within the locus coeruleus grafts (Fig. $5 d$ ). In the ventral mesencephalic grafts, dense areas of TH-positive neurons were often seen (Fig. $6 e$ ). Additionally, areas with no TH-immunoreactive cells were innervated by $\mathrm{TH}$-positive nerve terminals; that is, the grafts were divided into either cell or nerve terminal dense areas. Host brain surrounding the ventral mesencephalic grafts was reinnervated by $\mathrm{TH}$-immunoreactive nerve fibers that covered approximately one-third of host dorsal striatum (Fig. $5 \mathrm{c}$ ). Close to the graft, an almost normal nerve fiber density was found, while adjacent to the noninnervated areas, the nerve terminal density was low.

In the grafts with tissue containing arcuate nucleus, numerous TH-immunoreactive cells were found (Figs. $5 a, 6 b, d$ ). These

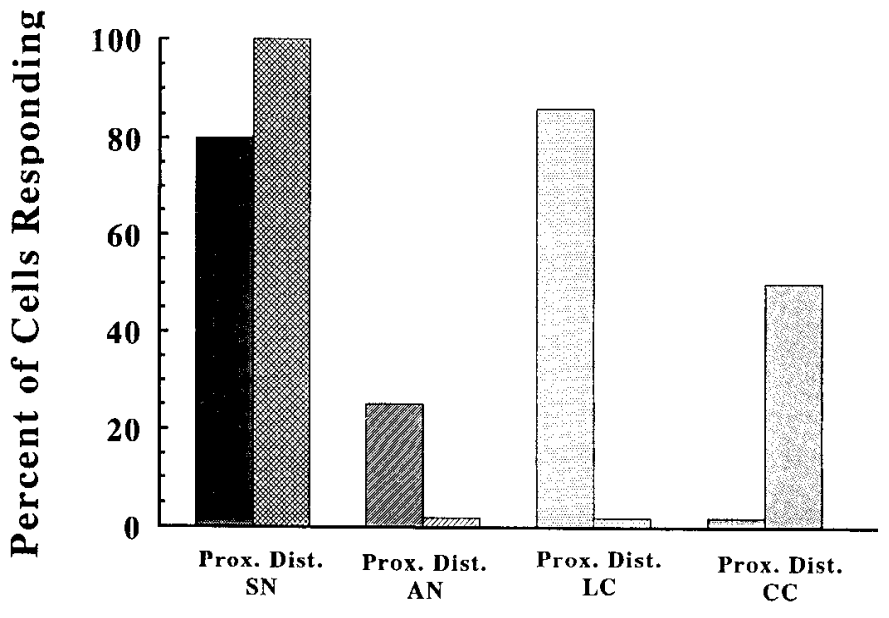

Figure 4. Percentage of cells responsive to local applications of PCP in grafted striata. Ninety percent of the neurons in animals that had received fetal mesencephalic grafts responded to PCP. Only a small percentage of neurons responded to PCP in animals with arcuate nucleus grafts, and all of these were proximal to the graft. A high percentage of neurons adjacent to locus coeruleus grafts were responsive to PCP, but neurons distal to the grafts were not responsive. With the grafts of cortical neurons, a small percentage of neurons were responsive to the PCP. These distal responsive cells were from one electrode pass.

neurons were evenly distributed throughout the total volume of the graft. A subpopulation of TH-positive neurons in arcuate grafts showed a lower fluorescence intensity, but were approximately of the same size and shape as TH-immunoreactive cells with intense fluorescence. Moreover, a dense nerve fiber network was found within the graft arca. In contrast to the rich reinnervation from ventral mesencephalic transplants, no nerve terminals grew into host brain from arcuate nucleus grafts (Fig. $6 b)$.

In locus coeruleus transplants, fewer $\mathrm{TH}$-immunoreactive neurons were found, but the nerve fiber density within the graft area was approximately as high as that seen within the ventral mesencephalic grafts (Figs. 5b, 6c). In host striatum of animals grafted with locus coeruleus, nonterminal fibers were seen with TH immunohistochemistry (Fig. 5b). These nerve fibers had a thicker diameter than those seen in striatum reinnervated by ventral mesencephalic grafts; however, their density was very low.

$\mathrm{DBH}$-positive neurons and nerve terminals were found in the locus coeruleus grafts (Fig. $5 d$ ), and a few DBH-immunoreactive nerve fibers with positive varicosities were also seen in host striatum. The $\mathrm{TH}$ - and $\mathrm{DBH}$-immunoreactive neurons in the locus coeruleus grafts appeared to have more spines on their dendrites than those seen in neurons in the ventral mesencephalic or arcuate nucleus transplants.

\section{Discussion}

Functional DAergic reinnervation of striatum in rats with unilateral 6-OHDA lesions was examined using the parameters of apomorphine-induced rotational behavior, striatal cell electrophysiological properties, and immunohistochemistry. As has been described by several investigators, grafts of fetal ventral mesencephalon to the lesioned striatum are capable of producing a functional DAergic reinnervation (Björklund and Stenevi, 1979; Perlow et al., 1979). This has been demonstrated as a reduction in the number of apomorphine-induced rotations following grafting. Additionally, there was a normalization of the 

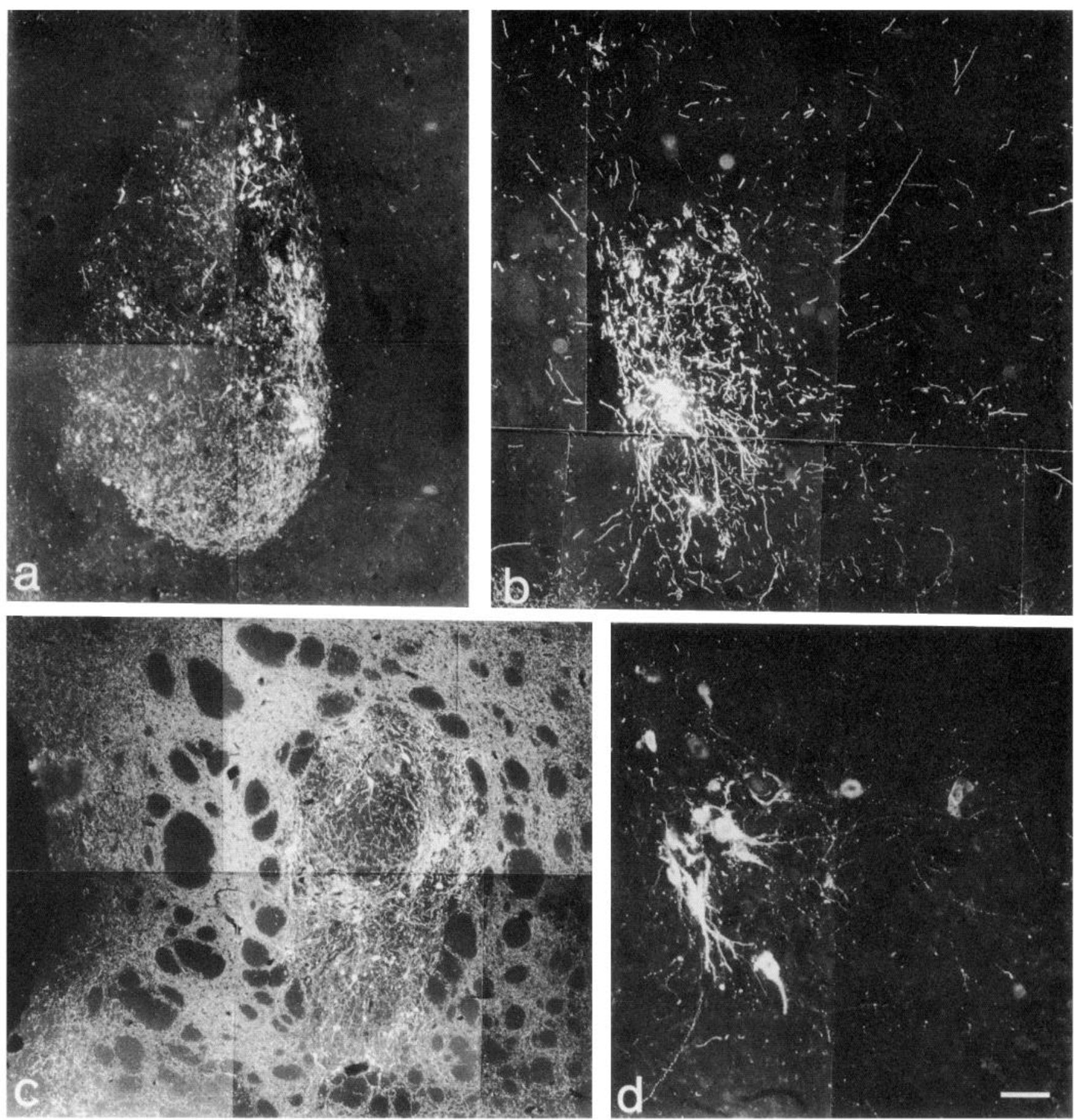

Figure 5. Immunohistochemical properties of transplanted striata: fetal tissue from arcuate nucleus $(a)$, locus coeruleus $(b)$, and ventral mesencephalon $(c)$ grafted to DA denervated striata visualized with TH immunohistochemistry. No TH-immunoreactive nerve fibers are crossing from the arcuate nucleus transplant into the host striatum $(a)$. In the locus coeruleus graft TH- $(b)$ and DBH- $(d)$ positive neurons are seen. Some thin DBH-immunoreactive varicose nerve terminals reinnervate the host striatum $(d)$. The only type of graft that substantially reinnervates the host striatum is from the ventral mesencephalic area $(c)$, where a dense nerve fiber network is seen close to, as well as far away from, the graft. Scale bar: $200 \mu \mathrm{m}$ for $a-c ; 100 \mu \mathrm{m}$ for $d$.

spontaneous striatal neuron firing rate, and a restitution of responses to local applications of PCP (Strömberg et al., 1985) Concurrently, the extent of reinnervation in that study, as assessed by Falck-Hillarp histochemistry, was extensive with such grafts.

In the present study, the fetal ventral mesencephalic grafts manifested all previous findings outlined above. In contrast,
DAergic neurons from the arcuate nucleus, which do not normally innervate the striatum, survive, grow, and even extend neurites in vivo; however, these neurites do not cross the hostgraft interface and no functional DAergic reinnervation of the host brain occurs. This postulate is supported by both the lack of behavioral recovery, in that apomorphine-induced turning was not decreased, and the electrophysiological data showing 

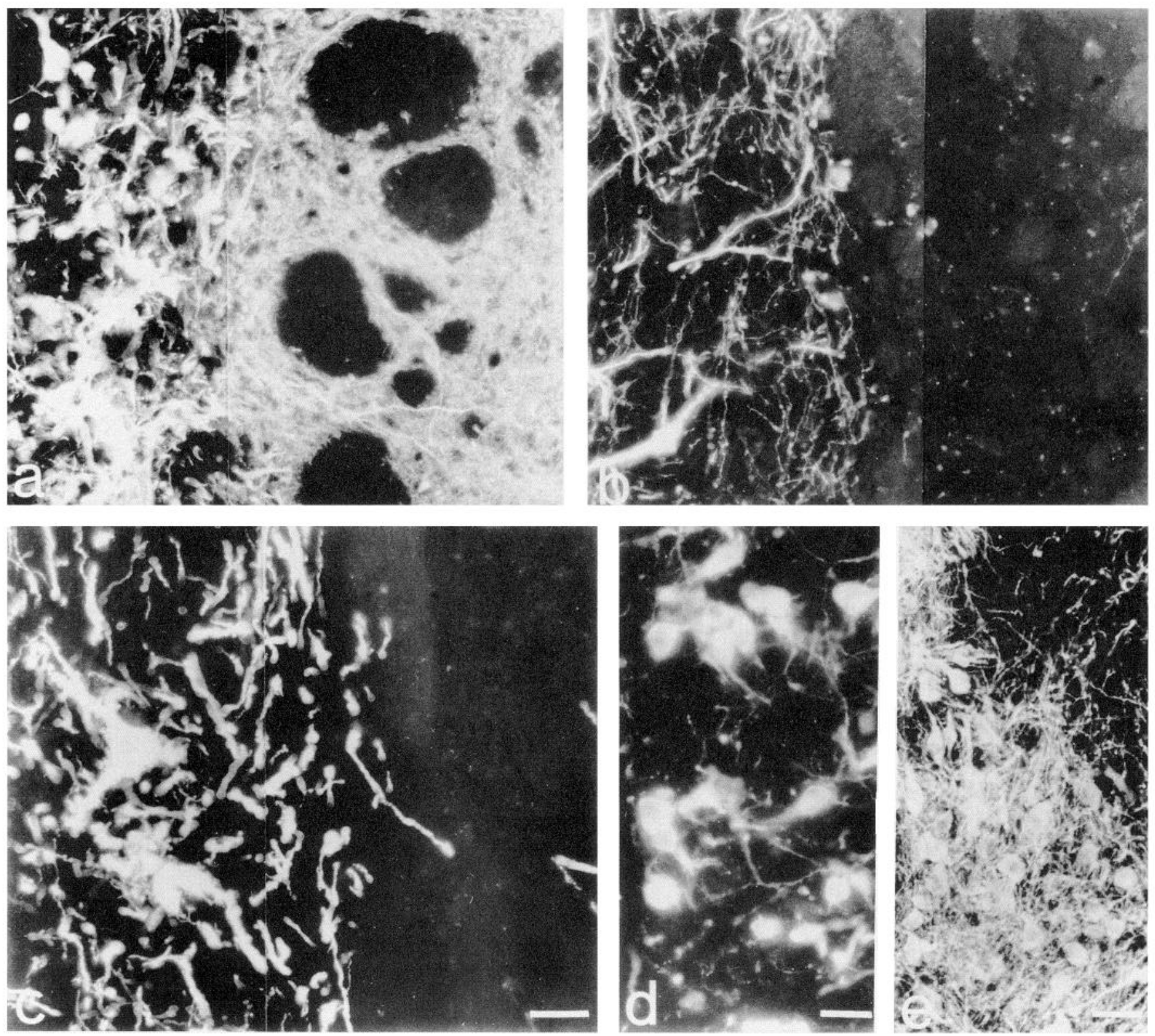

Figure 6. Immunohistochemical properties of grafted striata: photomicrographs showing TH immunohistochemistry of the border area between the graft (left side of each panel) and host striatum (right side of each panel) of ventral mesencephalon $(a)$, arcuate nucleus $(b)$, and locus coeruleus (c) implanted into DA denervated striata. A large number of TH-positive nerve fibers were found within the graft area of all types of grafts, but only in grafts of ventral mesencephalon were TH-positive nerve fibers found to innervate the striatal tissue at a high density. In the arcuate nucleus transplants, the TH-positive neurons are evenly spaced throughout the total area of the grafts $(d)$, while in the ventral mesencephalic transplants, the TH-immunoreactive neurons were concentrated only in some areas $(e)$. Scale bars: $a-c, 50 \mu \mathrm{m} ; d$ and $e, 100 \mu \mathrm{m}$.

that basal firing rates remained very high for striatal cells, similar to that seen after DA denervation alone. Only proximal to the grafts did a few cells respond to local applications of PCP. It is possible that this is due to local diffusion of DA from the graft into the striatum directly adjacent to the transplant; further studies using high-speed in vivo chronoamperometric techniques are needed to examine this possibility (van Horne et al., 1992).

In contrast to other evidence in which transplanted NAergic neurons change their phenotypic expression, and no longer express DBH when reinnervating the striatum (Nishino et al., 1990), we found that grafts of fetal locus coeruleus sent out only a few neurites into the host striatal parenchyma; the density of innervation was much less than that seen with ventral mesen- cephalic grafts. Moreover, locus coeruleus transplant-derived fibers and cell somas were both TH and DBH positive, suggesting that they were producing at least some norepinephrine. This is well documented with in oculo fetal brain grafts; they often retain their organotypic properties when transplanted to heterotypic sites (Woodward et al., 1977; Olson et al., 1985). In the present study, no reduction of turning was noted. Basal firing rates were also not normalized. Both these findings suggest that no functional reinnervation occurred.

The data reported here thus support the concepts of target determination of fiber ingrowth, derived from previous studies of in oculo grafts. DAergic ventral mesencephalic graft fibers, but not NAergic locus coeruleus graft fibers, will reinnervate an 
adjacent striatal transplant (Olson et al., 1979). Similarly, NAergic locus coeruleus graft fibers, but not DAergic ventral mesencephalic graft neurites, will reinnervate an adjacent hippocampal transplant (Olson et al., 1979). Moreover, both in oculo (Olson et al., 1985) and in situ (Schultzberg et al., 1984) graft-derived cholecystokinin-containing fibers will grow into ventral but not dorsal striatal targets. In terms of the arcuate grafts, our data also support the work of Sladek et al. (1986), who demonstrated ingrowth of neurites from DAergic but not hypothalamic neurons into MPTP-lesioned monkey striatum.

Several mechanisms could wholly or in part be responsible for the differential abilities of fetal grafts to provide a functional reinnervation in our system. Cell surface recognition molecules could play a large role in the ability of neurites to grow out into adult host brain (Schnell and Schwab, 1990). The type, density, and distribution of cell adhesion molecules such as N-CAM, for example, could have important effects on specificity (Edelman, 1984b; Rutishauser and Jessell, 1988; Takeichi, 1988). The absence or presence of positive or negative growth factors may also play a major role in axonal outgrowth. Many laboratories have shown the effects of growth factors on neuronal cells (Thoenen and Barde, 1980; Davies et al., 1986; Morrison et al., 1986; Blottner et al., 1989; Ernsberger et al., 1989).

In summary, DAergic neurons from the ventral mesencephalon are able to provide a functional input to the DA denervated striatum, while at the same time manifesting an immunohistochemical reinnervation. In contrast, grafts of DAergic neuroblasts that do not normally innervate the striatum, NAergic neuroblasts that normally do not project to the striatum, or nonCA neuroblasts that normally do extend axons into the striatum are unable to provide normalization of basal cell firing ratcs or PCP responsivity, or cause an extensive $\mathrm{TH}$-immunoreactive reinnervation of the denervated striatum. Therefore, both target specificity and neurotransmitter type of fetal CNS grafts are important for functional CAergic reinnervation. Thus, grafttarget specificity may be of the utmost importance for extensive functional reinnervation to occur.

\section{References}

Arbuthnott GW (1974) Proceedings: spontaneous activity of single units in the striatum after unilateral destruction of the dopamine input. J Physiol (Lond) 239:121P-122P.

Archer SM, Dubin MW, Stark LA (1982) Abnormal development of kitten retino-geniculate connectivity in the absence of action potentials. Science 217:743-745.

Björklund A, Stenevi U (1979) Reconstruction of the nigrostriatal dopamine pathway by intracerebral nigral transplants. Brain Res 177: $555-560$.

Blottner D, Bruggemann W, Unsicker K (1989) Ciliary neurotrophic factor supports target-deprived preganglionic sympathetic spinal cord neurons. Neurosci Lett 105:316-320.

Carman LS, Gage FH, Shults CW (1991) Partial lesion of the substantia nigra: relation between extent of lesion and rotational behavior. Brain Res 553:275-283.

Davies AM, Thoenen H, Barde YA (1986) The response of chick sensory neurons to brain-derived neurotrophic factor. J Neurosci 6:1897-1904.

Dubin MW, Stark LA, Archer SM (1986) A role for action-potential activity in the development of neuronal connections in the kitten retinogeniculate pathway. J Neurosci 6:1021-1036.

Edelman GM (1984a) Modulation of cell adhesion during induction, histogenesis, and perinatal development of the nervous system. Annu Rev Neurosci 7:339-377.

Edelman GM (1984b) Cell adhesion and morphogenesis: the regulator hypothesis. Proc Natl Acad Sci USA 81:1460-1464.

Ernsberger U, Sendtner M, Rohrer H (1989) Proliferation and differ- entiation of embryonic chick sympathetic neurons: effects of ciliary neurotrophic factor. Neuron 2:1275-1284.

Faber DS, Korn H (1989) Electrical field effects: their relevance in central neural networks. Physiol Rev 69:821-863.

Fisher LJ, Young SJ, Tepper JM, Groves PM, Gage FH (1991) Electrophysiological characteristics of cells within mesencephalon suspension grafts. Neuroscience 40:109-122.

Gerhardt GA, Palmer MR (1987) Characterization of the techniques of pressure ejection and microiontophoresis using in vivo electrochemistry. J Neurosci Methods 22:147-159.

Gerhardt GA, Pang K, Rose GM (1987) In vivo electrochemical demonstration of the presynaptic actions of phencyclidine in rat caudate nucleus. J Pharmacol Exp Ther 241:714-721.

Hudson JL, Levin DR, Hoffer BJ (1991a) A sixteen-channel automated rotometer system for reliable measurement of turning behavior in 6-hydroxydopamine lesioned rats. J Neurosci Methods, in press.

Hudson JL, van Horne CG, Strömberg I, Clayton J, Brock S, Masserano J, Hoffer BJ, Gerhardt GA (1991b) Correlation of apomorphineand amphetamine-induced turning behavior with nigrostriatal dopamine depletion. Soc Neurosci Abstr 17[Pt 2]:493.1.

Jaffe LF, Nuccitelli R (1977) Electrical controls of development. Annu Rev Biophys Bioeng 6:445-476.

Johnson GD, Nogueira Araujo Gm (1981) A simple method of reducing the fading of immunofluorescence during microscopy. J Immunol Methods 43:349-350.

Johnson SW, Haroldsen PE, Hoffer BJ, Freedman R (1984) Presynaptic dopaminergic activity of phencyclidine in rat caudate. J Pharmacol Exp Ther 229:321-332.

Levi-Montalcini R (1964) The nerve growth factor. Ann NY Acad Sci 118:149-168.

Lynch G, Matthews DA, Mosko S, Parks T, Cotman C (1972) Induced acetylcholinesterase-rich layer in rat dentate gyrus following entorhinal lesions. Brain Res 42:311-318.

Lynch G, Gall C, Rose G, Cotman C (1976) Changes in the distribution of the dentate gyrus associational system following unilateral or bilateral entorhinal lesions in the adult rat. Brain Res 110:57-71.

Morrison RS, Sharma A, de Vellis J, Bradshaw RA (1986) Basic fibroblast growth factor supports the survival of cerebral cortical neurons in primary culture. Proc Natl Acad Sci USA 83:7537-7541.

Nisenbaum ES, Stricker EM, Zigmond MJ, Berger TW (1986) Longterm effects of dopamine-depleting brain lesions on spontaneous activity of type II striatal neurons: relation to behavioral recovery. Brain Res 398:221-230.

Nishino H, Hashitani T, Kumazaki M, Ishida $Y$, Hida H, Makino T, Sakurai T, Furuyama F, Isobe Y, Sato H (1990) Phenotypic plasticity of locus coeruleus noradrenergic neurons after transplantation into the dopamine-depleted caudate in the rat. Prog Brain Res 82: 515-521.

Olson L, Seiger A, Hoffer B, Taylor D (1979) Isolated catecholaminergic projections from substantia nigra and locus coeruleus to caudate, hippocampus and cerebral cortex formed by intraocular sequential double brain grafts. Exp Brain Res 35:47-67.

Olson L, Vanderhaeghen JJ, Freedman R, Henschen A, Hoffer B, Seiger A (1985) Combined grafts of the ventral tegmental area and nucleus accumbens in oculo. Histochemical and electrophysiological characterization. Exp Brain Res 59:325-337.

Orr WB, Stricker EM, Zigmond MJ, Berger TW (1987) Effects of dopamine depletion on the spontaneous activity of type I striatal neurons: relation to local dopamine concentration and motor behavior. Synapse 1:461-469.

Perlow MJ, Freed WJ, Hoffer BJ, Seiger A, Olson L, Wyatt RJ (1979) Brain grafts reduce motor abnormalities produced by destruction of nigrostriatal dopamine systcm. Scicnce 204:643-647.

Ramon y Cajal S (1910) Algunas oservaciones favorables a la hipotesis neurotropica. Trab Lab Invest Biol Univ Madrid 8:63-134.

Ramon y Cajal S (1959) Degeneration and regeneration of the nervous system. New York: Hafner.

Robinson KR (1985) The responses of cells to electrical fields: a review. J Cell Biol 101:2023-2027.

Rutishauser U, Jessell TM (1988) Cell adhesion molecules in vertebratc ncural development. Physiol Rev 68:819-857.

Rutishauser U, Gall WE, Edelman GM (1978) Adhesion among neural cells of the chick embryo. IV. Role of the cell surface molecule CAM in the formation of neurite bundles in cultures of spinal ganglia. $\mathbf{J}$ Cell Biol 79:382-393. 
Schnell L, Schwab ME (1990) Axonal regeneration in the rat spinal cord produced by an antibody against myelin-associated neurite growth inhibitors. Nature 343:269-272.

Schreyer DJ, Jones EG (1982) Growth and target finding by axons of the corticospinal tract in prenatal and postnatal rats. Neuroscience 7:1837-1853.

Schultzberg M, Dunnett SB, Björklund A, Stenevi U, Hokfelt T, Dockray GJ, Goldstein M (1984) Dopamine and cholecystokinin immunoreactive neurons in mesencephalic grafts reinnervating the neostriatum: evidence for selective growth regulation. Neuroscience 12: 17-32.

Shatz CJ, Stryker MP (1988) Prenatal tetrodotoxin infusion blocks segregation of retinogeniculate afferents. Science 242:87-89.

Siggins G, Hoffer B, Ungerstedt U (1974) Electrophysiological evidence for the involvement of cyclic adenosine monophosphate in dopamine responses of caudate neurons. Life Sci 15:779-792.

Sladek J, Collier T, Haber S, Roth RH, Redmond DE (1986) Survival and growth of fetal CA neurons transplanted into primate brain. Brain Res Bull 17:809-818.

Sretavan DW, Shatz CJ, Stryker MP (1988) Modification of retinal ganglion cell axon morphology by prenatal infusion of tetrodotoxin. Nature 336:468-471.

Stenevi U, Björklund A, Svendgaard NA (1976) Transplantation of central and peripheral monoamine neurons to the adult rat brain: techniques and conditions for survival. Brain Res 114:1-20.

Strömberg I, Herrera-Marschitz M, Ungerstedt U, Ebendal T, Olson L (1985a) Chronic implants of chromatfin tissue into the dopaminedenervated striatum. Effects of NGF on graft survival, fiber growth and rotational behavior. Exp Brain Res 60:335-349.
Strömberg I, Johnson S, Hoffer B, Olson L (1985b) Reinnervation of dopamine-denervated striatum by substantia nigra transplants: immunohistochemical and electrophysiological correlates. Neuroscience 14:981-990.

Strömberg I, Bygdeman M, Almqvist P (1992) Target-specific outgrowth from human mesencephalic tissue grafted to cortex or ventricle of immunosuppressed rats. J Comp Neurol 315:445-456.

Takeichi M (1988) The cadherins: cell-cell adhesion molecules controlling animal morphogenesis. Development 102:639-655.

Thoenen H, Barde YA (1980) Physiology of nerve growth factor. Physiol Rev 60:1284-1335.

Ungerstedt U (1968) 6-Hydroxy-dopamine induced degeneration of central monoamine neurons. Eur J Pharmacol 5:107-110.

Ungerstedt U (1971a) Striatal dopamine release after amphetamine or nerve degeneration revealed by rotational behaviour. Acta Physiol Scand [Suppl] 367:49-68.

Ungerstedt U (1971b) Postsynaptic supersensitivity after 6-hydroxydopamine induced degeneration of the nigro-striatal dopamine system. Acta Physiol Scand [Suppl] 367:69-93.

van Horne CG, Hudson JL, Hoffer BJ, Gerhardt GA (1992) Diffusional properties of dopamine in a rat model of Parkinson's Disease as measured by multiple in vivo electrochemical detector arrays. Soc Neurosci Abstr 18[Pt 2]:581.13.

Weiss $P$ (1947) The problem of specificity in growth and development. Yale J Biol Med 19:235-278.

Woodward DJ, Seiger A, Olson L, Hoffer BJ (1977) Intrinsic and extrinsic determinants of dendritic development as revealed by Golgi studies of cerebellar and hippocampal transplants in oculo. Exp Neurol 57:984-998. 